\title{
"ENEGRECENDO O FEMINISMO": A OPÇÃO DESCOLONIAL E A INTERSECCIONALIDADE TRAÇANDO OUTROS HORIZONTES TEÓRICOS
}

\author{
"BLACKENNNG FEMINISM": THE DECOLONAL OPTION AND \\ INTERSECTIONALITY TRACING OTHER THEORETICAL HORIZONS
}

\section{RESUMO}

Os feminismos negros vêm prestando um grande serviço às epistemologias feministas e aos estudos sobre racismo. Ao tensionarem a omissão do feminismo branco em relação às pautas antirracistas, as mulheres negras expuseram a fragilidade das tendências universalistas. $\mathrm{O}$ convite aqui posto, inspirado numa revisão preliminar da literatura, é à imersão nas pautas, protagonismos e produção de conhecimento da e sobre as mulheres negras, a partir do lugar de fala da mulher negra. A perspectiva descolonial é utilizada nesse artigo como caminho teórico que evidencia a urgência em visibilizar e garantir o direito a voz às mulheres negras, sem desconsiderar o recorte de classes, o objetivo consiste na valorização de narrativas e subjetividades ainda subalternizadas. Nesse sentido, concluímos que a opção descolonial, racializada e generificada, oferece mais fundamentos para a análise das estruturas sociais a partir e por aqueles/as que lutam pelo direito a voz, escuta e visibilidade.

Palavras-chave: Descolonialismo. Feminismos Negros. Interseccionalidade.

\begin{abstract}
Black feminisms have been giving a great service to feminist epistemologies and studies on racism. By stressing the omission of white feminism against anti-racist standards, black women exposed the fragility of universalist tendencies. The invitation here, inspired by a preliminary review of the literature, is the immersion in the patterns, protagonism and production of knowledge of and about black women, from the speaking place of a black woman. The decolonial perspective is used in this article as a theoretical path that evidences the urgency of giving visibility and guaranteeing the right to voice to black women, without disregarding the social class cut, the objective is to value narratives and subalternized subjectivities. In this sense, we conclude that the decolonial, racialized and gendered option offers more foundation for the analysis of social structures from and for those who struggle for the right to voice, listening and visibility.
\end{abstract}

Keywords: Decolonialism. Black Feminisms. Intersectionality.

Natércia V. Bambirra

Universidade Federal de Santa Catarina. Email: natercianvb@hotmail.com

Teresa Kleba Lisboa

Universidade Federal de Santa Catarina. Email: tkleba@gmail.com 


\section{Introdução}

A sub-representação das mulheres negras na política, nos espaços acadêmicos e estudos que envolvem essas atrizes sociais, aliada a crescentes episódios de violências de gênero e racismo que tem ocorrido no cotidiano dos Campus Universitários nos provoca a revisar as dimensões, incômodos e desafios do que significa ter um corpo marcado pelo gênero e pela raça em locais e contextos fortemente segregacionistas. O exercício de "dar-se conta" dessa realidade aliado ao esforço de não naturalizar violências ${ }^{1}$ e sub-representações implicaram no entendimento de que podemos e devemos contribuir na visibilização de pautas e protagonismos das mulheres negras. Esses sujeitos contam com uma práxis histórica de lutas contra o racismo, o machismo e outras tantas formas de opressões, resistem às violências, as tentativas de apagamento e seguem em luta.

Nos apoiamos na fala de Lélia Gonzalez (1984: 225), ainda tão atual, para quem "enquanto mulher[es] negra[s], sentimos a necessidade de aprofundar nessa reflexão, ao invés de continuarmos na reprodução e repetição dos modelos que nos eram oferecidos pelo esforço de investigação das ciências sociais". Assim, "[e]xatamente porque temos sido falados, infantilizados (infans, é aquele que não tem fala própria, é a criança que se fala na terceira pessoa, porque falada pelos adultos)", que neste artigo, uma das autoras assume o seu lugar de fala enquanto mulher negra, e outra, enquanto mulher branca, buscando convergências, desestabilizando, criando fissuras e tensionamentos a fim de fazer emergir contra discursos e narrativas construídas a partir de outros referenciais e subjetividades ainda subalternizadas.

Nesse sentido, destacamos que graças às lutas travadas por grupos feministas e de mulheres, ao longo de décadas, as questões abordadas pelo feminismo branco, como as discriminações de gênero, divisão de trabalho por gênero, entre outras, vêm sendo largamente debatidas e estudadas. Não obstante, as mulheres negras, dentre outros sujeitos, e seus direitos ainda ficam à margem desses debates, bem como de políticas públicas próprias para, entre outras coisas, acessar créditos, moradia, creches, programas de saúde que atendam suas particularidades, condições que poderiam possibilitar a reconfiguração de suas vidas ${ }^{2}$. Esses fatos, entre outros, vêm sendo tensionados pelos feminismos negros e têm sido publicizados para desmistificar a categoria universalista de "mulher", posto que as tentativas de homogeneização dessa atriz social têm encoberto as diferentes formas de experienciar "ser mulher".

1 Inclusive porque uma das autoras foi alvo de violências de gênero e racismo em meio acadêmico, se tornando parte das estatísticas de violências de gênero e racial.

2 Segundo dados do Ministério do Desenvolvimento Social e Combate à Fome (MDS), "[d]as 19 milhões de pessoas que saíram da extrema pobreza com a ação Brasil Carinhoso, entre 2012 e 2013, 77\% são negras". (Disponível em: <http://mds.gov.br/area-de-imprensa/noticias/2013/dezembro/populacaonegra-e-a-maior-beneficiaria-de-programas-sociais-no-brasil >. Acesso em 21/05/2018). Ainda de acordo com o mesmo órgão, das mais de 13 milhões de famílias atendidas pelo programa Bolsa Família, 93\% dos/as titulares do cartão do programa são mulheres e 68\% negras. (Disponível em: <http:// www.brasil.gov.br/cidadania-e-justica/2013/o9/mulheres-representarm-93-da-titularidade-do-bolsafamilia>. Acesso em 21/05/2018). 
Para Sandra Harding (1996: 18), "temos que reconhecer que nas culturas estratificadas tanto pelo gênero, quanto pela raça, o gênero sempre constitui uma categoria racial, e a raça uma categoria de gênero". Dessa forma, "as políticas públicas sexistas são diferentes para as pessoas do mesmo gênero, mas de diferente raça, e as políticas racistas são distintas para as mulheres e homens da mesma raça”.

A leitura articulada de diferentes categorias/marcadores sociais vem para ampliar o alcance do entendimento acerca das opressões e discriminações, bem como as distintas formas como os sujeitos são afetados. Kimberle Crenshaw reuniu essa ideia sob o termo interseccionalidade. "A interseccionalidade é uma conceituação do problema que busca capturar as consequências estruturais e dinâmicas da interação entre dois ou mais eixos da subordinação" (Crenshaw, 2002: 177).

Por meio desse artigo, pretendemos contribuir para a publicização da produção de conhecimentos de e sobre o protagonismo das mulheres negras nos movimentos feministas e antirracistas com recorte de classes, numa perspectiva descolonial. O objetivo consiste na valorização de narrativas e subjetividades ainda subalternizadas. Nos apoiaremos na produção de autores/as latino-americanos/as e demais pesquisadores/as da temática para marcar a opção descolonial, bem como para a contextualização dos feminismos negros, seu nascimento, contribuições e desafios.

\section{Lugares de fala e feminismos: um pouco de história}

Muito se tem discutido acerca do que vem a ser e de quem possui lugar de fala, nesse sentido, "O que é lugar de fala?", primeiro livro da coleção Feminismos Plurais, escrito por Djamila Ribeiro (2017), que aborda o feminismo negro, bem como as produções intelectuais de mulheres negras a partir das categorias raça, classe, gênero e sexualidade, vem contribuir para o debate acerca da temática.

Na obra ${ }^{3}$ em tela, Ribeiro se apoia em um extenso e bem fundamentado aporte teórico para defender a necessidade de trazer em perspectiva a localização dos corpos, a interseccionalidade e lugares de fala. A autora parte do pensamento de Grada Kilomba, Patricia Hill Collins, Linda Martín Alcoff e Gayatri Spivak, para desenvolver sua leitura acerca da teoria de lugar de fala. Em suma, na perspectiva de Ribeiro, tal teoria afirma que todos/as temos lugares de fala, pois somos/estamos

3 Aparecem falas e trabalhos de Sojourner Truth e o seu discurso "Acaso não sou uma mulher?", cujo primeiro registro, foi publicado em 21 de junho de 1851; da pesquisadora e ativista negra Lélia Gonzalez; da filósofa panamenha Linda Martín Alcoff, que questiona a epistemologia eurocêntrica dominante, bem como seu caráter universalista e tensiona "a necessidade de se pensar outros saberes" (Ribeiro, 2017: 27); Bell Hooks, feminista negra estadunidense, que retrata a construção das mulheres negras ligada a aspectos corporais e não ao desenvolvimento de pensamento crítico; a concepção de Grada Kilomba, psicóloga mestiça portuguesa, para quem "a mulher negra é o Outro do Outro, posição que a coloca num local de mais difícil reciprocidade" (Ribeiro, 2017: 38); o conceito outsider within (forasteira de dentro), da obra de Patricia Hill Collins; as reflexões que Sueli Carneiro realiza em torno das hierarquias de gênero impostas pelo racismo; o pensamento de Audre Lorde, feminista negra, caribenha e lésbica, que discute a importância de não hierarquizarmos opressões (Ribeiro, 2017: 49), entre outras. 
socialmente localizados. Não obstante, as implicações variam conforme a localização social do sujeito. Como exemplo, a autora cita o racismo no Brasil, assinalando que pessoas negras vão poder falar sobre esse tema na perspectiva de quem o sofre, enquanto que pessoas brancas poderão falar a partir de quem é beneficiado/a por essa opressão.

Uma vez referido o conceito de lugar de fala do qual partimos, faremos algumas considerações acerca dos feminismos negros nos Estados Unidos (EUA) e no Brasil, suas origens e importância para a luta das mulheres.

Mercedes Jabardo Velasco (2012: 27), argumenta que nos EUA “o movimento feminista negro surgiu na confluência (e tensão) entre dois movimentos, o abolicionismo e o sufragismo, em uma difícil intersecção. Embora com presença relevante em ambos, a combinação de racismo e sexismo excluiu as mulheres negras dos dois"”.

As mulheres negras estavam fortemente presentes na luta pela abolição da escravidão nos EUA, bem como nos movimentos feministas brancos que reivindicavam a igualdade dos direitos políticos por meio do sufrágio. Ocorre que, uma vez alcançada a abolição da escravidão o movimento feminista branco, pela incapacidade de perceber a intensificação da opressão quando raça e sexo eram relacionados, acabou excluindo as mulheres negras de sua pauta de lutas, tornandose um instrumento de opressão dessas mulheres. Isso causou a cisão do feminismo estadunidense, entre feminismo branco e feminismo negro (Davis, 2013).

Para Velasco (2012: 32), o final do século XIX e início do XX nos EUA foi marcado pela aliança entre homens e mulheres negras, frente a segregação imposta pelo movimento sufragista liderado pelo feminismo branco de origem burguesa. A autora advoga que, enquanto o feminismo branco moderno se desenvolve tendo por base a afirmação da filósofa branca Simone de Beauvoir de que "não se nasce mulher, torna-se mulher”, “(...) los discursos de género em el feminismo negro parten de una negación, de una exclusión, de un interrogante, el que retoma Bell Hooks de Sojourner Truthen uno de los primeros textos del pensamiento feminista negro: ¿Acaso no soy una mujer?”.

Uma outra diferença apontada pela autora entre o feminismo branco e o negro nos EUA consiste no fato de que, enquanto o primeiro tinha um caráter construtivista acerca da categoria mulher, o segundo se propunha a simultaneamente reclamar e reconstruir a identidade da mulher. Isso porque parte de uma não-categoria, ou seja, a mulher negra não é tida socialmente como pessoa ou como mulher, daí que os desafios são bem maiores, bem como o conjunto de discriminações e opressões. Assim entendendo,

4 Tradução livre: "El movimiento feminista negro surgió en la confluencia (y tensión) entre dos movimientos, el abolicionismo y el sufragismo, en una difícil intersección. Aun teniendo una presencia relevante en ambos, la combinación de racismo y sexismo terminó excluyendo a las mujeres negras de los dos". 
[1]a única estratégia posible desde la negación es um ejercicio de de-construcción. Destruir la negación desde donde se ha excluido de la categoría de mujeres a las mujeres negras, para avanzar, repensarse y reconstruirse desde otras categorías. Reconocer las imágenes de no mujer como estrategias de hegemonía. Dotarse de las herramientas adecuadas para reflejarla y para superarla, unas herramientas que como disse Audre Lorde no podrán ser las herramientas del amo: «Las herramientas del amo nunca desmontan la casa del amo. (...)». Para dejar de ser constituidas como objetos y pensarse como sujetos, tuvieron que tomar la palabra, recuperar la voz y generar um nuevo discurso. En definitiva, crear una nueva epistemologia (Velasco, 2012: 33).

Outra contribuição de Velasco (2012: 45) nessa obra consiste na constatação de que, as feministas negras estadunidenses ao deslocarem o racismo para o epicentro das desigualdades, abriram espaço para o surgimento de outros feminismos, como é o caso do feminismo negro britânico. Essa atitude epistemológica e política agregou dados e informações acerca da diáspora ${ }^{5}$ de afrodescendentes.

Em relação ao Brasil, Sueli Carneiro (2011) afirma que tanto aqui como na América Latina, em geral a identidade nacional tem origem nas violências sexuais perpetradas pelos homens brancos donos de escravos/as contra mulheres negras e indígenas, resultando em uma população miscigenada. Tal fato, seria estruturante do mito da democracia racial. Para a autora,

... um feminismo negro, construído no contexto de sociedades multirraciais, pluriculturais e racistas - como são as sociedades latino-americanas - tem como principal eixo articulador o racismo e seu impacto sobre as relações de gênero, uma vez que ele determina a própria hierarquia de gênero em nossas sociedades (Carneiro, 2011).

Nesse sentido, Carneiro (2011) argumenta que os movimentos feministas negros ao denunciarem e combaterem as opressões de raça e gênero têm contribuído para a ação política feminista e anti-racista no cenário nacional. Além do mais, a articulação das categorias raça, gênero e classe tem enegrecido “(...) de um lado, as reivindicações das mulheres, tornando-as assim mais representativas do conjunto das mulheres brasileiras, e, por outro lado, promovendo a feminização das propostas e reivindicações do movimento negro".

5 J. Lorand Matory (1999: 70), por meio dos conceitos de nação territorial e transnacionalismo, direciona estudos na desconstrução da noção sustentada por estudiosos/as da cultura negra, na qual as pessoas escravizadas de África nas Américas "se originaram de grupos étnicos africanos cujas culturas preexistentes 'sobreviveram' na diáspora até elas desaparecerem aos poucos pelo processo de assimilação". Para o autor, alguns dos grupos africanos e afro-americanos de maior expressão são transatlânticos em sua gênese. 
Ainda nessa linha de pensamento, para Carneiro (2003: 118) a expressão "enegrecendo o feminismo" designa o percurso realizado pelas mulheres negras "no interior do movimento feminista brasileiro". O objetivo é trazer ao debate o fato de que o feminismo brasileiro, reproduzindo uma tendência colonial, assimilou uma identidade branca e ocidental, além de "revelar a insuficiência teórica e prática política para integrar as diferentes expressões do feminino construídos em sociedades multirraciais e pluriculturais". Dessa forma, para a autora tal expressão tornou possível "engendrar uma agenda específica que combateu, simultaneamente, as desigualdades de gênero e intragênero; afirmamos e visibilizamos uma perspectiva feminista negra que emerge da condição específica do ser mulher, negra e, em geral, pobre", além de demonstrar o necessário envolvimento do movimento feminista na luta antirracista no Brasil.

Carneiro (2003: 119) afirma que as perspectivas das mulheres dos grupos subalternizados tensionam a diversificação das concepções e práticas políticas no feminismo e promove "de um lado a afirmação das mulheres em geral como novos sujeitos políticos, de outro exige o reconhecimento da diversidade e desigualdades existentes entre essas mesmas mulheres". Esse fato tem reflexos em diferentes aspectos da vida social. Trataremos de algumas interfaces referentes ao mercado de trabalho, violências, saúde e meios de comunicação, amparadas em Carneiro.

Nas lutas protagonizadas pelas mulheres negras em prol da igualdade de oportunidades e salários no mercado de trabalho, a inclusão de questões afetas a raça, que atuam como barreiras que reforçam a estratificação social, são postas no centro das discussões. Já em relação a violência, os movimentos de grupos subalternizados, e no que diz respeito a esse trabalho os movimentos feministas negros, além de denunciarem as diferentes expressões da violência que atingem a população negra e sobremaneira as mulheres negras, para além da violência física ${ }^{6}$ e sexual visibiliza a violência racial, resultante da hegemonia da branquitude (Carneiro, 2003).

No âmbito da saúde e dos direitos reprodutivos, Carneiro (2003: 123/124) advoga que as contribuições do feminismo negro consistem na colocação dessas pautas na agenda de luta antirracista, além do "reconhecimento das diferenças étnicas e raciais nessa temática”. Nesse sentido, a autora destaca a importância da luta das mulheres negras para a implantação do Programa de Anemia Falciforme do Ministério da Saúde (PAF/MS) que se trata de uma "anemia hereditária e constitui a doença genética mais comum da população negra”. No Brasil, a doença atinge cerca de $10 \%$ da população, majoritariamente negros/as ou seus/as descendentes.

Os reflexos do racismo nos meios de comunicação têm demonstrado a falta de representatividade da população negra em postos de poder, além da reificação

6 O Mapa da Violência 2015: homicídios de mulheres no Brasil (2015: 29/30), demonstrou que: "[c] om poucas exceções geográficas, a população negra é vítima prioritária da violência homicida no País; [a]s taxas de homicídio da população branca tendem, historicamente, a cair, enquanto aumentam as taxas de mortalidade entre os negros. (...) O número de homicídios de [mulheres] brancas cai de 1.747 vítimas, em 2003, para 1.576, em 2013. Isso representa uma queda de 9,8\% no total de homicídios do período. Já os homicídios de [mulheres] negras aumentam $54,2 \%$ no mesmo período, passando de 1.864 para 2.875 vítimas". 
de estereótipos, tais como do homem negro malandro, marginal e a sexualização exacerbada da mulher negra, sua coisificação e manutenção em postos de trabalho subalternizados.

Em suma, trabalhamos até aqui com a desconstrução da categoria "mulher", que carrega um aspecto universalizante pautado até então pelos feminismos brancos. As grandes responsáveis pelo feito na América Latina foram as mulheres negras (em articulação com movimentos de mulheres camponesas de origem indígena) que organizaram as pautas de gênero de forma interseccionada com a agenda antirracista. Além do mais, vimos que os movimentos feministas negros no Brasil e no mundo têm contribuído tanto com os movimentos feministas brancos, quanto com os movimentos antirracistas. Ainda nesse sentido, é inegável a relevância da teoria do lugar de fala, que trabalha com a ideia da localização dos corpos, na articulação de pautas feministas e antirracistas a partir do entendimento das diferenças de "onde se fala".

No próximo item apresentaremos a opção descolonial como caminho para elucidar a importância, bem como a urgência da publicização das narrativas a partir dos lugares de fala das mulheres negras e, em sua maioria, pobres.

\section{Descolonizando o saber: a opção descolonial no entendimento de estruturas marcadas pela raça, gênero e classe}

Para entendermos as possíveis contribuições do pensamento descolonial para a análise das estruturas de sociedades marcadas pela raça, gênero e classe, como é o caso do Brasil, nos embasaremos no pensamento de integrantes do Grupo Modernidade/Colonialidade (Grupo $\mathrm{M} / \mathrm{C}$ ), constituído por intelectuais latinoamericanos, - Aníbal Quijano, Walter Mignolo e Ramón Grosfoguel - e da teórica feminista María Lugones.

Começaremos com as colocações de Grosfoguel para quem,

... parte do mito eurocêntrico é que vivemos numa chamada era "pós"-colonial e que o mundo e, em especial, os centros metropolitanos, não necessitam de descolonização. Segundo esta definição convencional, a colonialidade é reduzida à presença de administrações coloniais. Porém, como comprovou o trabalho do sociólogo peruano Aníbal Quijano (1993, 1998, 2000) com a sua perspectiva da "colonialidade do poder", continuamos a viver num mundo colonial e temos de nos libertar das formas estreitas de pensar as relações coloniais, de modo a concretizar esse inacabado e incompleto sonho do século XX que é a descolonização. Isto obriga-nos a examinar novas alternativas coloniais utópicas, que vãoalém dos fundamentalismos eurocêntricoe "terceiromundista" (Grosfoguel, 2008: 128). 
As considerações de Grosfoguel nos servem de introdução ao pensamento de Quijano (2002: 4), que parte da discussão das questões centrais do processo de globalização, perpassando pelo tema do poder, enquanto relação social, e seus elementos - dominação, exploração e conflito. Tais elementos tocam "as quatro áreas básicas da existência social e que são resultado e expressão da disputa pelo controle delas", quais sejam, o trabalho e suas implicações; o sexo e suas implicações; a autoridade coletiva (ou pública) e suas implicações; a subjetividade/intersubjetividade e suas implicações. Assim, as formas de existência social no âmbito de cada uma dessas áreas consistem em um complexo estrutural histórico e específico, ou seja, são sempre um determinado padrão histórico de poder.

Para o autor, o atual padrão de poder mundial consiste na articulação entre a colonialidade do poder - a partir da raça -, o capitalismo, o Estado - enquanto detentor do controle da autoridade -, e o eurocentrismo - que coloca países europeus em posição hegemônica, sobretudo na produção de conhecimentos.

Nesse sentido, cabem as considerações de Grosfoguel

Contrariamente ao que afirma a perspectiva eurocêntrica, a raça, a diferença sexual, a sexualidade, a espiritualidade e a epistemologia não são elementos que acrescem às estruturas económicas e políticas do sistema-mundo capitalista, mas sim uma parte integrante, entretecida e constitutiva desse amplo "pacote enredado" a que se chama sistema-mundo patriarcal/capitalista/ colonial/moderno europeu (Grosfoguel, 2002) (Grosfoguel, 2012: 128).

Walter Mignolo (2009: 263/264) afirma que a perspectiva decolonial vem para romper com a concepção na qual a realidade é vista sob uma perspectiva ocidental hegemônica. O pensamento decolonial está situado na exterioridade, ou seja, numa perspectiva realizada por e a partir de quem está fora para se construir o que está dentro. Em suma, o problema, para a opção decolonial é a decolonização do saber e do ser. "De ahí la diferencia epistémica y ontológica colonial a partir de la cual reclaman sus derechos epistémicos (y no su privilegio) quien es han sido dejados fuera del juego y de las decisiones".

Mignolo (2009) afirma que enquanto opção, o decolonialismo não é a única maneira de ler a realidade, a opção decolonial se orienta para a pluri-versalidade como projeto universal.

O autor advoga que tanto o cristianismo, quanto o liberalismo e o marxismo, tendem a se colocar como expressão única, totalitária de entendimento da realidade. O marxismo, por exemplo, analisa a forma que adquire a matriz colonial no século XVIII, com enfoque no aspecto econômico, a opção decolonial a seu turno, busca entender a formação histórica da matriz colonial de poder no século XVI, com enfoque na gestão econômica, da autoridade, do gênero e da sexualidade, da subjetividade 
e do conhecimento, entendendo que é o controle do conhecimento o instrumento fundamental de domínio e controle das demais instâncias.

Para Mignolo (2009), ocorreram mudanças da retórica da humanidade e embora os conteúdos tenham se modificado, os termos da conversação permanecem os mesmos, ou seja, pautados na lógica da colonialidade. Não obstante, há dois elementos fundamentais que não sofreram modificações, quais sejam, a dispensabilidade da vida e as quatros esferas inter-relacionais da matriz colonial de poder (economia, autoridade, gênero e sexualidade, conhecimento e subjetividade), mediante o controle do conhecimento que é racista e patriarcal.

Aqui, a intereseccionalidade pode nos auxiliar na visibilização dos corpos historicamente marcados, pela interação entre gênero, raça e classe, além de demonstrar a maior vulnerabilidade das mulheres negras pobres face aos demais grupos sociais. Grosfoguel se utiliza da interseccionalidade para demonstrar o "enredamento"

... de múltiplas e heterogéneas hierarquias globais ("heterarquias") de formas de dominação e exploração sexual, política, epistémica, económica, espiritual, linguística e racial, em que a hierarquia étnico-racial do fosso cavado entre o europeu e o não-europeu reconfigura transversalmente todas as restantes estruturas globais de poder. O que a perspectiva da "colonialidade do poder" tem de novo é o modo como a ideia de raça e racismo se torna o princípio organizador que estrutura todas as múltiplas hierarquias do sistema-mundo (Quijano, 1993). (...) A ideia de raça organiza a população mundial segundo uma ordem hierárquica de povos superiores e inferiores que passa a ser um princípio organizador da divisão internacional do trabalho e do sistema patriarcal global. (Grosfoguel, 2002) (Grosfoguel, 2012: 128).

Em María Lugones (2014: 935), há o entendimento de que “(...) a modernidade organiza o mundo ontologicamente em termos de categorias homogêneas, atômicas e separáveis". Aqui está presente a crítica das mulheres negras de países emergentes ao universalismo feminista, embasada na ausência de reflexões sobre as intersecções entre raça, classe e gênero, que acabam se "adequando" ao pensamento colonial, sem dar-se conta do conjunto de opressões/explorações que atingem desigualmente as mulheres.

A partir das concepções de colonialidade em Quijano, Lugones (2014) desenvolve seu pensamento acerca da colonialidade do gênero. O termo, objetiva nomear uma classificação de povos em termos de colonialidade de poder e de gênero, bem como o processo de redução ativa das pessoas, a desumanização, o processo de sujeitificação e a investida de negar ao/a colonizado/a a humanidade.

Lugones (2014), seguindo as concepções teóricas de Juan Ricardo Aparicio e Mario Blaser, nomeia de não-modernas as organizações sociais nas quais pessoas têm resistido à modernidade capitalista e estão em tensão com esta lógica. Por seu 
turno, a modernidade nega a existência desses grupos ao roubar-lhes a validez e a coexistência no tempo. Além disso, há o apagamento político, onde a tensão vivida do linguagismo constitui a lealdade à colonialidade de gênero ao apagar a história de resistência a partir da diferença colonial.

Para Lugones (2014), por meio da hierarquia dicotômica entre o humano e o não-humano, marca-se a civilização. Só os/as civilizados/as são homens ou mulheres. Aos povos indígenas das Américas e aos/as africanos/as escravizados/as era negada a humanidade e também o gênero, assim, tais povos eram entendidos e tratados como animais, sexualizados e selvagens. Em outras palavras, na colonialidade do gênero racializada se percebia o sexo existindo isoladamente na caracterização de colonizados/as. Desse ponto de vista, os/as colonizados/as tornaram-se machos e fêmeas, posto que o gênero era característica da civilização. A humanização dos/as colonizados/as não era uma meta colonial.

Não obstante as tentativas do colonialismo moderno de gênero de apagar a cosmologia, os costumes, a língua e a história dos povos colonizados, além da negação de sua humanidade que "legitimou" durante séculos sua exploração, inclusive sob a tutela e conivência da Igreja por meio das "missões eclesiásticas", importante salientar que sempre houve e há resistências (Lugones, 2014). A resistência é entendida por Lugones, como a tensão entre a sujeitificação (a formação/informação do sujeito) e a subjetividade ativa.

Nesse sentido, a relevância do pensamento de Lugones está assentada nas tentativas de compreender as mais diversas estratégias de resistência que os povos colonizados fazem uso e que se expressam com mais fervor no campo infrapolítico. A escolha pela atuação nesse campo consiste em uma estratégia, na medida em que a esses grupos de resistência, é negada a subjetividade oposicionista por meio da deslegitimação, silenciamento, confusão de sentido e invisibilização de suas pautas.

No Brasil, essa questão é consubstanciada sob o mito da democracia racial, ainda fortemente reproduzido pelo senso comum e por instituições estatais. Ao negar a existência do racismo e paralelamente trabalhar com a ideia de meritocracia, são desenrolados vários efeitos. Primeiramente, se a existência do racismo é negada, em tese não são necessárias ações do Estado para erradicar tal prática, como investimentos em conscientização, sensibilização, fiscalização, punição e políticas públicas. Além disso, ao reafirmar o mérito, como se todos/as tivessem igualdade de condições, mais uma vez o Estado é eximido de seu dever de atuar na mitigação das desigualdades criadas com base nas diferenças raciais. Outro efeito consiste na responsabilização do/a indivíduo/a, ou seja, se todos/as tem igualdade de condições e a raça não é determinante da estratificação socioeconômica, o motivo de grande parte das pessoas negras não acessarem creches e universidades públicas, terem auto índice de evasão escolar, não acessarem uma rede de saúde pública bem equipada para atender suas especificidades, ser maioria em conglomerados urbanos (favelas e quebradas), ou ainda, não conseguirem maior qualificação profissional e consequentemente maior remuneração, é porque tais pessoas não se esforçam suficientemente. Todos esses efeitos conduzem a invisibilização das pautas específicas 
de mulheres e homens negros/as, à deslegitimação das mesmas, bem como preserva o mito da democracia racial, que em última instância não passa de uma tentativa de naturalizar a institucionalização do racismo.

Para González,

A primeira coisa que a gente percebe, nesse papo de racismo é que todo mundo acha que é natural. Que negro tem mais é que viver na miséria. Por quê? Ora, porque ele tem umas qualidades que não estão com nada: irresponsabilidade, incapacidade intelectual, criancice, etc e tal. Daí, é natural que seja perseguido pela polícia, pois não gosta de trabalho, sabe? Se não trabalha, é malandro e se é malandro é ladrão. Logo, tem que ser preso, naturalmente. Menor negro só pode ser pivete ou trombadinha (González, 1979b), pois filho de peixe, peixinho é. Mulher negra, naturalmente, é cozinheira, faxineira, servente, trocadora de ônibus ou prostituta. Basta a gente ler jornal, ouvir rádio e ver televisão. Eles não querem nada. Portanto têm mais é que ser favelados (González, 1984, p. 225/226).

Não obstante, podemos citar algumas conquistas que se refletem em ações do Estado no combate ao racismo e a discriminação racial como resposta as pressões e reivindicações do movimento negro. Nesse sentido, é possível perceber alguns avanços no âmbito jurídico culminando na inclusão do inciso XLII, do art. $5^{\circ}$ na Constituição Federal de 1988, que determina que "a prática do racismo constitui crime inafiançável e imprescritível, sujeito de reclusão nos termos da lei”, entre outros, bem como a promulgação da Lei Caó ${ }^{7}$ e do Estatuto da Igualdade Racial ${ }^{8}$. No campo das ações afirmativas e políticas públicas, após a criação em 2003 da Secretaria Especial de Políticas de Promoção da Igualdade Racial (SEPPIR), observamos a criação e implementação de vários programas, como o Programa de Combate ao Racismo Institucional (PCRI) e ações de implementação da Lei no 10.639/2003, que estabelece a obrigatoriedade da inclusão no currículo do Ensino Básico do estudo da História e da Cultura Afro-Brasileira, entre outras (Jaccoud, 20o8). A Associação Brasileira de Pesquisadores/as Negros/as (ABPN), que recém completou 18 anos, tem constituído um espaço de discussão e de pressão muito importante. Nela, as mulheres negras vêm desempenhando um papel relevante em todas as instâncias.

Carneiro aduz que

... o protagonismo político das mulheres negras tem se constituído em força motriz para determinar as mudanças nas concepções e o reposicionamento político feminista no Brasil. A ação política das mulheres negras vem promovendo:

7 Lei no 7.716 , de 05 de janeiro de 1989.

8 Lei no 12.288 , de 20 de julho de 2010. 
- o reconhecimento da falácia da visão universalizante de mulher;

- o reconhecimento das diferenças intragênero;

- o reconhecimento do racismo e da discriminação racial como fatores de produção e reprodução das desigualdades sociais experimentadas pelas mulheres no Brasil;

- o reconhecimento dos privilégios que essa ideologia produz para as mulheres do grupo racial hegemônico;

- o reconhecimento da necessidade de políticas específicas para as mulheres negras para a equalização das oportunidades sociais; - o reconhecimento da dimensão racial que a pobreza tem no Brasil e, conseqüentemente, a necessidade do corte racial na problemática da feminização da pobreza;

- o reconhecimento da violência simbólica e a opressão que a brancura, como padrão estético privilegiado e hegemônico, exerce sobre as mulheres não brancas (Carneiro, 2003: 129/130).

Lugones (2014) denuncia o processo de colonização pela invenção/o dos/as colonizados/as, essa invenção vem sendo reproduzida e ainda habita o imaginário de pesquisadores/as e do senso comum. A título ilustrativo, Heleieth Saffioti argumenta que à mulher negra,

[d] e acordo com o modelo oficial, cabem-lhe, fundamentalmente, dois papéis: o de empregada doméstica e o de objeto sexual. (...) o homem branco construiu o mito da negra ou mulata sensual. (...) Interessa ao homem branco aumentar este mito, pois, por tradição, está habituado a 'usar sexualmente' negras ou mulatas (Saffioti, 1987: 52/53).

Em consonância com as colocações e reivindicações dos feminismos negros, Lugones (2014) propõe a descolonização do gênero enquanto práxis e convida os feminismos a pensar criticamente a opressão de gênero numa perspectiva racializada, colonial e capitalista heterossexualizada visando uma transformação vivida do social. Além disso, para Lugones (2014: 950/951), a tarefa das feministas descoloniais têm início no ato de "dar-se conta" da diferença colonial e, a partir daí, enfaticamente resistir ao seu próprio hábito epistemológico de apagá-la. Ademais, a autora convida feministas e pesquisadoras a se colocarem "no lugar das outras", nos dedicando ao exercício de entendermos nossos lugares de fala e onde nos situamos na diferença colonial para que possamos construir "uma nova sujeita de uma nova geopolítica feminista de saber e amar".

Os/as autores/as acima citados/as fornecem base para a utilização da opção descolonial para compreendermos como as estruturas de poder, hierarquizadas pela classe social, se forjaram no nosso país tendo como fundamento a racialização dos sujeitos, bem como o gênero. 
A colonização das subjetividades e do saber tem como efeito, entre outras coisas, garantir cientificidade, e assim legitimidade, a determinadas produções de conhecimentos e seus/as autores/as. Gonzalez criticava a hierarquização dos saberes "como produto da classificação racial (...). A consequência dessa hierarquização legitimou como superior a explicação epistemológica eurocêntrica” (Ribeiro, 2017: 24/25).

A conjunção das opressões de raça, gênero e classe apontam para aqueles sujeitos que estão mais vulneráveis dentro das estruturas sociais, estamos falando das mulheres negras e pobres. A opção descolonial oferece mais fundamentos para a análise das desigualdades sociais numa perspectiva racializada e generificada, a partir e por aqueles/as que têm sido invisibilizados/as e silenciados/as. Nesse sentido, as produções, práxis e apontamentos dos feminismos negros têm refletido o engajamento daqueles/as que lutam por uma sociedade onde a diferença não gere a discriminação e apagamento.

\section{Considerações finais}

Os movimentos feministas negros vêm prestando um grande serviço as epistemologias feministas e aos estudos sobre racismo. Isso porque tensionam as inúmeras formas de se experienciar "ser mulher" e desafiam os movimentos feministas e antirracistas, bem como o próprio Estado a incluir, respectivamente, em suas pautas e políticas públicas demandas e especificidades direcionadas a um público historicamente marcado.

A perspectiva descolonial ao sublinhar a colonização do conhecimento e das subjetividades, bem como trabalhar a partir das narrativas de quem historicamente foi mantido/a a margem, possibilita entre outras coisas a valorização desses saberes, além da visibilização e voz dos/as subordinados/as, no caso do estudo em comento, das mulheres negras. A interseccionalidade das categorias raça/etnia, gênero e classe auxiliam no entendimento.

Acreditamos que ecoar as vozes, lutas e a produção de conhecimento da e sobre a população negra, em particular das mulheres negras, é uma forma de romper com a colonização de nossos corpos e subjetividades de um lado, e de outro lado reconhecer não apenas lugares de fala, mas conferir legitimidade ao discurso, bem como às práticas e estratégias daqueles/as cuja existência é marcada por discriminações, lutas e resistências. 


\section{Referências bibliográficas}

BLACKWELL, Maylei; NABER, Nadine. (2002). Interseccionalidade em uma era de globalização as implicações da Conferência Mundial Contra o Racismo para práticas feministas transnacionais. Disponível em:< http://www.scielo.br/pdf/ref/v1on1/11637. pdf >. Acesso em: 12 nov. 2017.

CARNEIRO, Sueli. (2011). Enegrecer o Feminismo: a situação da mulher negra na américa latina a partir de uma perspectiva de gênero. Disponível em: <https://www. geledes.org.br/enegrecer-o-feminismo-situacao-da-mulher-negra-na-americalatina-partir-de-uma-perspectiva-de-genero/>. Acesso em 13 de fev. 2018.

CARNEIRO, Sueli. (2003). Mulheres em movimento. Disponível em: <http://www. scielo.br/pdf/ea/v17n49/1840o.pdf>. Acesso em 13 de fev. 2018.

CRENSHAW, Kimberle W. (2004). A intersecionalidade na discriminação de raça e gênero. In: VV.AA. Cruzamento: raça e gênero. Brasília: Unifem.

DAVIS, Angela. (2013). Mulheres, raça e classe. Tradução Livre. Plataforma Gueto.

GONZALEZ, Lélia. (1984). Racismo e Sexismo na Cultura Brasileira. In: Revista Ciências SociaisHoje, ANPOCS, p. 223-244.

GROSFOGUEL, Ramón. (2008). Para descolonizar os estudos de economia política e os estudos pós-coloniais: transmodernidade, pensamento de fronteira e colonialidade global. Tradutora: Inês Martins Ferreira. Revista Crítica de Ciências Sociais, 80: 115147.

HARDING, Sandra. (1996). Del problema de la mujer en la ciencia al problema de la ciencia en el feminismo. In: Ciencia y Feminismo. Capítulo I. Madrid: Ediciones Morata, S.L., p. 15-27.

JACCOUD, Luciana. (2008). O combate ao racismo e à desigualdade: o desafio das políticas públicas de promoção da igualdade racial. In: As políticas públicas e a desigualdade racial no Brasil: 120 anos após a abolição. Mário Theodoro (org.), Luciana Jaccoud, Rafael Osório, Sergei Soares. Brasília: Ipea, p. 131/166.

LUGONES, María. (2014). Rumo a um feminismo descolonial. Revista Estudos Feministas, CFH/CCE/UFSC, vol. 22, n. 3, p.935-952.

MATORY, J. Lorand. (1999). Jeje: Repensandonações e transnacionalismo. Mana.5(1):57-80. 
MIGNOLO, Walter. (2009). La Idea de América Latina (laderecha, laizquierda y laopcióndecolonial). In: CyE,Año I, n. 2, Primer Semestre, p. 252-276.

QUIJANO, Aníbal. (2002). Colonialidade, poder, globalização e democracia. In: Novos Rumos: Instituto Astrojildo Pereira,n. 37, p. 04-28.

RIBEIRO, Djamila. (2017). O que é lugar de fala? Belo Horizonte: Letramento: Justificando.

SAFFIOTI, Heleieth Iara Bongiovani. (2009). Ontogênese e filogênese do gênero: ordem patriarcal de gênero e a violência masculina contra mulheres. Disponível em: <http://flacso.redelivre.org.br/files/2015/o3/Heleieth_Saffioti.pdf>. Acesso em 3 de fev. 2018.

VELASCO, Mercedes Jabardo. (2012). Introducción. Construyendo puentes: en diálogo desde / conel feminismo negro. In:TRUTH, Sojourner; et al. Feminismos negros: una antologia. Traficantes de sonhos: mapas, p. 27/56.

WAISELFISZ, Julio Jacobo. (2015). Mapa da Violência 2015: homicídios de mulheres no Brasil. Disponível em: <http://www.mapadaviolencia.org.br/mapa2015_mulheres. php>. Acesso em o6 de jan. 2018. 